\section{A internacionalização do movimento zapatista: a presença da solidariedade de classe transnacional em chiapas ${ }^{1}$}

\section{The Zapatista movement internationalization: the presence of transnational classe solidarity in Chiapas}

\author{
D0I: 10.5752/P.2317-773X.2017v5.n3.p73
}

Davi Matias Marra Demuner ${ }^{2}$

Recebido em: 15 de junho de 2017.

Aceito em: 25 de novembro de 2017.

\begin{abstract}
RESUMo
Este artigo tem o objetivo de analisar a experiência do movimento zapatista em sua coordenação de forças sociais que transcendem a dimensão local/nacional, alcançando a solidariedade transnacional acerca de sua resistência frente ao Estado mexicano e na construção de um projeto político alternativo em Chiapas. Por meio do framework de classes e a concepção de hegemonia de Antonio Gramsci, recorremos a momentos relevantes do curso histórico do movimento para entender a partir de quais elementos discursivos ocorre a prática social zapatista revolucionária em convergência com o auxílio material e ideológico da sociedade civil internacional. Entendemos que apesar da influência externa gerada pela sua práxis em Chiapas, o zapatismo não se desterritorializa em meio as dimensões geopolíticas da guerra de posição na globalização - entendida pelos zapatistas como uma "quarta guerra mundial" - e atua em associação com ONG/ONGI, sem deixar a crítica acerca do processo de transformismo que essas organizações podem acarretar sobre os movimentos sociais.
\end{abstract}

Palavras-chave: Zapatismo. Solidariedade de classe. Globalização. Resistência anticapitalista.

\begin{abstract}
This article aims to analyze the zapatista movement experience in its coordination of social forces that transcend the local/national dimension, achieving transnational solidarity on its resistance to the Mexican State and the construction of an alternative political project in Chiapas. Through class framework and the hegemony concept of Atonio Gramsci, we turn to relevant moments in the historical course of the movement to understand from which discursive elements the revolutionary zapatista social practice occurs, in convergence with the material and ideological aid of international civil society. We understand that, despite the external influence generated by his praxis in Chiapas, the zapatismo does not deterritorialize itself between the geopolitical dimensions of the war of position in globalization - understood by the zapatistas as a "fourth world war" - and operates in association with NGO/INGOs, without leaving the criticism about the process of transformismo that these organizations can make on social movements.
\end{abstract}

1. Este artigo faz parte da dissertação defendida pelo autor denominada "0 movimento zapatista e a solidariedade de classe transnacional: Uma análise da luta de classes na globalização"
2. Mestre pelo Programa de Pós-graduação em Relações Internacionais (PPGRI) da Universidade Federal de Uberlândia (UFU). Membro do grupo "Marx e Gramsci" coordenado pela Profa. Ana Maria Said da UFU. Orcid: https://orcid. org/0000-0003-3154-5030.

Keywords: Zapatism. Class solidarity. Globalization. Anticapitalist resistance. 
Introdução

O conceito de "hegemonia" é recorrentemente citado na disciplina de Relações Internacionais (RI), contudo o seu significado pode ter variações e aplicações distintas (ROBINSON, 2005). A palavra é derivada da língua grega, do substantivo hegemon - aquele que mostra o caminho - e do verbo hegeisthai - guiar/liderar (SABONMATSU, 2004). Neste artigo entendemos hegemonia em termos gramscianos, isto quer dizer que a expressão se refere ao momento em que um determinado grupo exerce o seu poder por intermédio de sua posição de dominante e dirigente na sociedade. O entendimento da hegemonia no Estado ampliado (sociedade política mais sociedade civil) estende o espectro das forças sociais, contribuindo para o debate marxista acerca da reprodução dos privilégios da classe burguesa em seus níveis materiais e ideológicos (ALVES 2010).

O famoso artigo de Cox (1981) Social Forces, States and World Orders: Beyond International Relations Theory retoma este conceito de hegemonia para evidenciar a estreita relação da produção científica de RI com a manutenção dos problemas do cenário internacional. Além da crítica, neste mesmo artigo cabem recomendações para realizar pesquisas no campo internacional sem recair na "instrumentalização da razão", buscando desse modo um conhecimento que fosse emancipatório. Para tanto, o positivismo das teorias hegemônicas da área não pode seguir reificando as relações internacionais, em contraposição, o materialismo histórico é capaz de explicar/superar as forçais sociais existentes na formação de determinada Ordem Mundial. Junto a isto, a análise crítica deve levar em consideração que teoria e prática estão inter-relacionadas na produção de conhecimento, bem como na construção de nossa realidade, sendo possível através da razão crítica entender quais são as estruturas de dominação do sistema capitalista, e alterá-las por meio de ações sociais concretas (COX, 1981).

A proposta deste artigo se encaixa nessa abordagem das RI que se convencionou classificar enquanto neogramsciana. A fim de um entendimento do que se busca e do que é criado no exemplo zapatista, as duas categorias (teoria e prática) devem ser entendidas em conjunto e dialeticamente. Propõe-se então uma análise do discurso zapatistas acerca das forças sociais transnacionais de resistência presentes na construção do projeto político autônomo no México, no estado de Chiapas. Desse modo, o estudo de caso aqui se insere numa perspectiva crítica a respeito da (possível) consciência de classe que se forma diante da globalização e seus reflexos na criação de novas sociabilidades anticapitalistas, para além do modelo mainstream nos estudos sobre a solidariedade transnacional, baseado principalmente no framework de captação de recursos e opinião pública.

A arquitetura da globalização e os seus arquitetos

O discurso da globalização enquanto fenômeno inevitável dos elevados fluxos de capital e comunicação serve para legitimar as práticas neoliberais voltadas para a abertura dos mercados nacionais e a ausência declarada do Estados na administração de setores sociais e públicos. A globalização é em si um fenômeno mundial resultante dos interesses de 
classe, causado pelas forças sociais originadas nos conflitos entre os movimentos "de cima" e "de baixo" da sociedade (NILSEN, 2009).

A formação de blocos históricos e as hegemonias exercidas no interior das sociedades do Estado-nação moderno com suas respectivas relações sociais de produção produzem forças sociais que caracterizam as relações internacionais, bem como os fenômenos internacionais influenciam na realidade doméstica, portanto, no modo de produção e na forma que os Estados adquirem (COX, 1983). Entendendo a relação nodal das forças locais e globais na formação nacional (Estado) e internacional (Ordem Mundial) no desenvolvimento desigual e combinado da globalização é possível percebermos qual classe mais se beneficia/prejudica com as políticas adotadas e os principais mecanismos adotados neste processo. Assim, "aqui formação e conflito de classe mediam entre a produção da economia mundial e o sistema interestatal. As classes (...) possuem suas origens em sociedades nacionais, mas formam links entre as fronteiras que separam as sociedades nacionais" (COX, 1987, p. 357).

A necessidade de compreender as forças sociais que engendram a configuração do capitalismo global estimulou os estudos sociológicos a respeito das associações em rede geradas pela fração da classe capitalista que se transnacionaliza para garantir seus interesses liberalizantes nas relações internacionais, sobretudo após a crise do modelo de acumulação keynesiano no decorrer dos anos 70, majoritariamente entre corporações e elites do Atlântico Norte (CARROLL, 2010). Entende-se a formação de um bloco histórico articulado pela Classe Capitalista Transnacional (CCT), a qual constrói a sua agenda econômica/política nos espaços de integração da sociedade civil entre os diretores executivos das grandes corporações transnacionais. E a projeta nas instituições de governança global - Organizações Internacionais (OIs), fóruns da sociedade civil, Regimes Internacionais - por meio do aparato político-legal do Estado, devido ao seu posicionamento hegemônico no contexto nacional (ROBINSON, 2005).

Neste sentido, as corporações transnacionais agem diretamente na sistematização em nível global do modelo de desenvolvimento neoliberal, e para isso a CCT não se constitui apenas da fração corporativa, mas também das frações: estatal, técnica e consumista. É a partir da aliança estabelecida entre as grandes corporações com diversos partidos políticos, com profissionais de OIs e setores midiáticos que torna possível a tese da CCT (SKLAIR, 2002). A rede criada no circuito do capital nacionalmente ganha forma para além das fronteiras, e se estabelecem redes transnacionais que sugerem um nível de consciência de classe entre esses atores componentes da CCT capaz de influenciar os arranjos da governança global, os quais sejam capazes de realizar inclusive a manutenção dos interesses antagonistas da CCT, por exemplo, os sistemas de resolução de controvérsias da Organização Mundial do Comércio (OMC) (ROBINSON, 2007).

Contudo, isto não quer dizer, por exemplo, que a CCT se originou neste mesmo período, sendo causa/efeito do próprio processo de globalização. Através do estudo histórico realizado por Kes van der Pijl (1997) entendemos o desenvolvimento das redes estabelecidas por esta classe, bem 
3. Entendemos como zapatismo o movimento social praticado pelos indígenas e camponeses que se organizam coletivamente no território de Chiapas após o conflito armado dos guerrilheiros com o governo do México. Assim, podemos nos direcionar ao "zapatismo militar" se referindo ao corpo do exército revolucionário presente na organização do projeto político, ou ao "zapatismo civil", isto é, os membros dos Municípios Autônomos Rebeldes Zapatistas (MA REZ) que constroem a autonomia sem necessariamente participar do exército

(ROVIRA, 2005).

4. Carranza antes de assumir a presidência (1917 - 1920) foi responsável por liderar a constituinte que levou à criação da Constituição de 1917 , que adiciona no artigo 27 o direito ao modelo de organização social em terras coletivas denominadas ejidos, mas que só foi institucionalizado de fato sob o comando de Lázaro Cárdenas (1934 -

1940) (VAZOUEZ-CASTILLO, 2004). como as pressões realizadas sobre elas, até chegar ao seu apogeu na Economia Política Global (EPG). Retomando desde o início da formação do sistema interestatal, o autor caracteriza dois tipos ideais de formas de Estado em que podemos inserir as tipologias coxianas: (i) Contenders hobessianos, para indiciar o modelo mercantilista fechado e com a gerência estatal plena nos setores doméstico; (ii) Heartland lockeano, em referência ao modelo inglês pós-revolução gloriosa, no qual o Estado garantia os direitos de propriedade privada e permitia a reprodução dos interesses da sociedade civil. Por meio das influências ideológicas (religião, partidos, etc.) e materiais (necessidade de exportação, abertura comercial) historicamente nas relações internacionais o autor demonstra a construção de sua condição de classe até a formação do bloco histórico atual (VAN DER PIJL, 1997).

Um fator relevante para a propagação do consenso em torno do modelo de desenvolvimento neoliberal é o "novo constitucionalismo", o qual se refere à crença na democracia liberal-burguesa enquanto único modelo de organização política viável/eficiente, após o colapso das experiências socialistas. De modo que qualquer tentativa de projeto político que transborde a perspectiva limitada de democracia no liberalismo é considerada uma ameaça para a estabilidade da Ordem Mundial. Em consonância com o "neoliberalismo disciplinador", uma forma de poder do capital responsável por moldar e vigiar o espaço global para a perfeita aplicação da espoliação, eliminando as possibilidades de políticas macroeconômicas distintas a fim de garantir a plena aplicação dos cálculos matemáticos e evitar possíveis "distúrbios" do sistema monetário internacional. Encontramo-nos, então, no domínio da "civilização de mercado", que diz respeito à mercantilização em todos os níveis da vida dos indivíduos, assim a lógica da acumulação capitalista se torna a base das interações sociais, desde o Estado/mercado até o cotidiano (GILL, 2008)

Diversos movimentos sociais eclodem como resposta à mercantilização das relações sociais na estratégia de acumulação neoliberal, o zapatismo ${ }^{3}$ é um deles. O Exército Zapatista de Libertação Nacional (EZLN) surge no interior da Selva Lacandona em 1983, porém a sua formação ocorre a partir da articulação de diferentes grupos políticos que já vinham sendo mobilizados anteriormente. O processo de revolução passiva pelo qual passou o México após a crise da estratégia de acumulação desenvolvimentista ocasionou diversas reformas estruturais para adequar a economia mexicana ao Acordo de Livre Comércio da América do Norte (ALCAN) (MORTON, 2013). A indignação com a nova forma do Estado se expandiu principalmente na região sul e agrícola, onde se localiza o estado da sublevação zapatista, Chiapas, posto a retirada dos ejidos ${ }^{4}$ enquanto direito constitucional por Salinas de Gortari em 1992 (BRANCALEONE, 2015).

Após o conflito armado em janeiro de 1994, mesma data da entrada do México no ALCAN, os zapatistas iniciaram o espaço de questionamento acerca do novo constitucionalismo e de discussão sobre o que, de fato, significa a democracia, consequentemente, as suas repercussões na realidade local/nacional dos subalternos, de modo que "a história do seu movimento cristaliza o nexo global-local” (DELLACIOPPA; WEBER, 
2012, p. 03). A guerra de posição5 exercida desde então pelos zapatistas possui como resultado a criação de laços orgânicos com diversas organizações independentes e outros movimentos sociais no México e na sociedade civil internacional ${ }^{6}$.

\section{A "quarta guerra mundial" e la otra economia política internacional}

a superação do capitalismo não se dá apenas na transformação do Estado, mas também, e, principalmente, por meio da construção do novo - aqui a práxis zapatista ${ }^{6}$ (OUVIÑA, 2013). Além disso, no sentido gramsciano, a luta só é efetiva, duradoura, quando esta também desempenha uma atividade militante na negação dos valores morais e intelectuais exercidos hegemonicamente sobre a sociedade pelo bloco histórico da classe capitalista através da criação do "bom senso" 7 no lugar do senso comum, enquanto crítica a respeito da naturalização de nosso mundo e agregador das dispersas lutas e opressões dos subalternos (BIELER \& MORTON, 2008; IVES, 2004). O que nos leva a refletir sobre as ideias decorrentes da resistência e experiências de novas sociabilidades.

Como espaço para a interlocução cultural da resistência, foi convocado o Primeiro Encontro Intercontinental pela Humanidade e Contra o Neoliberalismo na Primeira Declaração da Realidade. Dizem:

Renomeado como "neoliberalismo", o crime histórico da concentração de privilégios, riquezas e impunidades, democratiza a miséria e a desesperança. (...) Com o nome de "globalização" chamam essa guerra moderna que assassina e esquece (...) A nova divisão do mundo exclui as "minorias". Indígenas, jovens, mulheres, homossexuais, lésbicas, pessoas de cor, imigrantes, trabalhadores, camponeses; as maiorias que formam os porões mundiais são apresentadas, para o poder, como minorias dispensáveis. (EZLN, 2017a, tradução nossa).

A "globalização" é representada enquanto uma "guerra moderna", a manifestação política decorrente da concentração de poder no neoliberalismo. É contra essa "guerra" que os zapatistas convocam os seus aliados. Como resultado dessa guerra, os rebeldes representam as diversas formas de exclusão na uniformização disciplinar do neoliberalismo. A identidade indígena sempre presente na pauta zapatista não serve como limites para o seu diálogo com as demais "minorias". A partir do avanço na análise das opressões da Nova Esquerda, a amplitude das fraturas proporcionadas pela hegemonia, o entendimento da resistência que se faz à globalização não pode ser levado adiante com objetivos estritamente identitários, mas sim pela união entre aqueles que possuem o seu direito de ser e existir negado. Tanto nas declarações nacionais, quanto nesta em que existe um forte caráter internacional, o zapatismo representa o seu alinhamento ao lado dos subalternos que compõem a resistência mundial, unindo a luta contra a hegemonia no México com as demais agendas antissistêmicas.

Segue-se:

Contra a internacional do terror que representa o neoliberalismo, devemos levantar a internacional da esperança. A unidade, acima de fronteiras, línguas, cores, culturas, sexos, estratégias e pensamentos de todos aqueles que preferem a humanidade viva (...). Uma nova mentira nos é vendida como história. A mentira sobre a derrota da esperança, a mentira sobre a derrota da dignidade, a mentira sobre a derrota da humanida-
5. A transformação social nas sociedades ocidentais não poderia ser colocada em prática a partir apenas da tomada do aparelho estatal e dos meios de produção - guerra de movimento - como no caso das sociedades orientais. A complexidade da articulação capitalista na sociedade civil ocidental torna necessária uma guerra de posição, na qual a classe trabalhadora precisa promover a contestação dos valores pilares da legitimidade do status-quo da classe dirigente no espaço das macro e micro relações sociais (GRAMSCl, 2000). Ao caracterizarmos a estratégia zapatista como guerra de posição não estamos desconsiderando todo 0 aparato bélico/militar que se constitui o EZLN, ao contrário, entendemos as duas formas (guerra de movimento/guerra de posição) de maneira dialética e que se complementam, assim como as análises de Gramsci sobre a Revolução Russa.

6. Tomamos como sociedade civil internacional o amplo espaço de interação entre os atores das sociedades civis

nacionais que se articulam em rede transnacionalmente, o que "inclui não apenas ONGs, mas também as atividades de partidos políticos, igrejas, corporações de meios de comunicação, associações políticas e científicas, algumas progressivas, outras reacionárias" (GILL, 2008, p.247, tradução nossa), além das corporações transnacionais e os movimentos sociais. Trata-se, portanto, de um corpo heterogêneo e antagônico, diferente do discurso zapatista, pois como veremos, recorrentemente esse conceito aparece como um sinônimo para a resistência altermundialista.

7. A materialização da autonomia de facto perpassa por resistências que fogem do escopo das políticas de cooptação da hegemonia - de manutenção da inserção das classes subalternas no modo de produção capitalista - são táticas que podemos considerar como antirrevolução passiva. Isso se dá, sobretudo, pelos projetos do "bom governo" de saúde autônoma, educação autônoma e produção coletiva coordenados regionalmente pelas Juntas de Bom Governo (JBG) nos Caracóis (MORTON, 2013).

8. 0 "bom senso" zapatista e sua organização social se concretizam como forças sociais anti-restauração do status-quo a partir da dialética de construção/contestação por qual se estabelece a hegemonia no campo discursivo e prático. 
9. 0 plano foi um enorme investimento em infraestrutura para a exploração de recursos naturais (biopirataria), terra e trabalho na região da Mesoamérica, incluindo 5 estados do sul do México (dentre esses está Chiapas), países da América Central, Belize e Panamá. Contudo, diferente de outros planos até então, o PPP utiliza o discurso de "desenvolvimento sustentável" para reali-

zar a extração sem supostamente afetar os direitos indígenas. Desse modo, 0 ambientalismo das lutas camponesas se transforma em ferramenta de acumulação de capital para as corporações transnacionais (ROBINSON, 2008) de. O espelho do poder nos oferece um equilíbrio na balança: a mentira da vitória do cinismo, a mentira da vitória do servilismo, a mentira da vitória do neoliberalismo. (EZLN, 2017a, tradução nossa).

Conceitos considerados universais são recorrentemente retomados pelos zapatistas, como "dignidade", "justiça" e "liberdade", porém Hilsenbeck (2017) nos atenta para a contextualização desses termos na luta zapatista, os quais estão diretamente relacionados com uma noção de equidade social. Ao final, a menção aos expropriados dos meios materiais de subsistência, justiça, paz, independência e democracia perpassa pela própria questão da globalização. Mesmo que em outros momentos exista à repulsa pelo termo "unidade", principalmente para se referir aos aspectos totalitários do poder, aqui encontramos o seu uso de maneira positiva, como a união na luta pela dignidade, o que não significa a negação das diferenças e divergências.

A crítica ao pensamento da impossibilidade de mudança é retratada com a metáfora da "mentira da morte da esperança" e a "mentira da vitória do cinismo". A possibilidade de mudança é algo vivido no cotidiano pelos zapatistas, porque o seu cotidiano é a construção do projeto político que almejam. O papel dos movimentos sociais na construção "por baixo" da realidade na última passagem nos leva a refletir sobre os posicionamentos fatalistas da história.

Foram realizadas assembleias preparatórias em todos os continentes para preceder o evento, que se propôs a discutir os aspectos culturais, políticos, econômicos e sociais do neoliberalismo, como as lutas se resistem a eles, e levantar meios de resistência (EZLN, 2017a). De acordo com Khasnabish (2013), o Encontro Intercontinental aconteceu entre os dias 27 de julho e 3 de agosto de 1996 nos 5 Aguascalientes, e contou com a participação de mais de 5 mil pessoas de 42 países. Após o término, o Comitê Central Revolucionário Indígena (CCRI) anunciou a Segunda Declaração da Realidade como resultado do espaço de discussão. A representação da globalização como "guerra" é novamente colocada:

\footnotetext{
Globalização dos mercados é apagar as fronteiras para a especulação e o crime, multiplicando-os para os seres humanos (...). Neste mundo que o Poder se globaliza para evitar obstáculos em sua guerra de conquista, os governos nacionais são transformados em forças armadas de uma nova guerra mundial contra a humanidade. (...) O fim da "Guerra Fria" não impediu que a corrida armamentista no mundo, somente mudou o modelo do comércio mortal (EZLN, 2017b, tradução nossa).
}

O contexto de "liberalização" do discurso neoliberal baseado em princípios como liberdade e democracia, que serve como pilar moral e político do novo constitucionalismo - sobretudo no México - é criticado com a sua concretude: a abertura e conquista de novos mercados. Chiapas com o Plano Puebla-Panamá (PPP) e a exploração petrolífera, hoje comandada pelo capital estrangeiro na PEMEX, sempre foi um reflexo da transnacionalização da agenda econômica nacional na globalização. A revolução passiva nas relações internacionais trouxe formas de Estado no Sul Global que se caracterizam pelos abusos de poder coercitivo na supressão dos movimentos contestatórios, como forma de controle, de ordem, tão necessária ao volúvel sistema financeiro internacional, ainda que sob a aparência de democracia (MORTON, 2007). O fim da Guerra 
Fria é relacionado com a alteração do foco dos conflitos, que não deixam de existir, para os problemas internos do Estado nas agendas de Segurança Nacional, tal como a Guerra de Baixa Intensidade (GBI) nos municípios de governo zapatista.

Enquanto os zapatistas mencionam a existência de uma guerra mundial com o advento da globalização, outros indivíduos permanecem sem seu cotidiano conformados. Gill (1995a) ao caracterizar a civilização de mercado aponta para o conteúdo ideológico em seu ordenamento. $\mathrm{O}$ neoliberalismo se reproduz com o esquecimento, com a visão de mundo ahistórica que se torna hegemônica nas relações sociais principalmente por meio do discurso do "novo capitalismo", no qual as medidas econômicas e políticas são tomadas unilateralmente, pois são a única cabíveis (para manter o lucro) (FAIRCLOUGH, 2010). Ao mesmo tempo, nenhuma ideologia é imune à crítica, e a consciência da realidade concreta na globalização leva o sujeito a se indignar, bem como ao Estado a manter seu domínio, ainda que não mais por meio do consenso.

Por fim, como encaminhamento do Encontro, fruto dos debates sobre as formas de resistência ao neoliberalismo, decidiu-se pela criação de uma rede de articulação:

(...) faremos uma rede coletiva de todas as nossas lutas e resistências particulares. (...) buscará, reconhecendo diferenças e reconhecendo semelhanças, conhecer outras resistências em todo o mundo. (...) será o meio pelo qual as diferentes resistências se apoiaram mutuamente. (...) não é uma estrutura organizacional, não tem um centro de administração ou de tomada de decisão, não tem comando central ou hierarquias. Esta rede somos todos nós que resistimos. (...) faremos uma rede de comunicação entre todas as nossas lutas e resistência. (EZLN, 2017b, tradução nossa).

O fluxo de ativistas nas regiões zapatistas já havia demonstrado a sua importância na intervenção dos conflitos com o Estado. A "rede" já existia em sua forma mais abstrata, e na Internet páginas de informação sobre o contexto dos rebeldes demonstravam o seu desempenho, como era o caso de Ya Basta! e Chiapas95. Sem muitas pretensões para além do que já vinha se configurando, o encaminhamento serviu para estabilizar e ampliar os contatos da rede. Assim como Olesen (2004a) relata, apesar do movimento na rede ser algo difícil de se acompanhar, é notório como os espaços físicos de interação dos atores membros corrobora para o nível de organização da articulação. Daqui se retira algumas das principais características da rede de solidariedade transnacional zapatista: a horizontalidade e a troca de informação (OLESEN, 2004a). Evitar o silenciamento das lutas particulares, algo marcante no histórico zapatista, aparece nesse momento como o principal objetivo (KHASNABISH, 2013).

Guiomar Rovira (2005) caracteriza como "zapatismo transnacional" a frente que surge a partir da relação dos rebeldes zapatistas com outros atores da sociedade civil. A autora se refere à rede de solidariedade transnacional zapatista. É nesse sentido uma rede, pois em uma dinâmica horizontal e menos rígida no que envolve quais são as atividades de cada membro, os atores englobam organizações com objetivos e estratégias diferentes, os quais criam laços nodais a partir da interação de auxílio aos zapatistas. É possível se pensar nessa rede através da confluência de atores nacionais e não-nacionais no (i) auxilio material/financeiro à manutenção 
dos municípios rebeldes, na (ii) difusão para além das fronteiras de Chiapas do discurso anticapitalista criado pelo zapatismo contra a globalização de cima, bem como através de (iii) práticas que deslegitimam as ações coercitivas do governo (ROVIRA, 2005).

Nesse sentido, a rede transnacional se trata de uma coordenação entre as forças internacionais para seguir pensando uma superação ao neoliberalismo e motivando as lutas que seguem no caminho, e não a solução em si para os problemas encontrados em Chiapas (ou outro lugar do mundo) (CECEÑA, 2001; OLESEN, 2005). Se analisarmos essa proposta numa perspectiva maior de prazo, é possível relacioná-la com a criação da extensa rede de comunicação Ação Global dos Povos (AGP) em 1998. Após o Segundo Encontro Intercontinental pela Humanidade e Contra o Neoliberalismo realizado no ano posterior ao primeiro, na Espanha, a necessidade materializar os debates de modo mais concreto motivou o surgimento da organização. A amplitude da Batalha de Seattle em 1999 se deve, em certa medida, à atuação da AGP em torno das negociações da OMC (KHASNABISH, 2013).

Quase 10 anos depois do Primeiro Encontro Intercontinental, temos a Sexta Declaração da Selva Lacandona. Já com um acúmulo maior de conquistas e percas, a Sexta representou as mudanças estratégicas e organizacionais dos zapatistas depois das tentativas falhas de dialogar com o governo. Trata-se de um documento bastante rico em informações, no qual os zapatistas buscam explicar aos mexicanos e ao mundo quem são eles, porque eles estão na resistência, quais serão os seus objetivos políticos no cenário nacional, e a relação com as demais lutas que na rede de solidariedade que se formou.

A Outra Campanha, o projeto de alterar as relações políticas do Estado com a sociedade civil mexicana por baixo, não se tratou de uma iniciativa unicamente nacional. Pelo contrário, mais uma vez os atores progressistas da sociedade civil internacional foram convidados a compor as novas das atividades zapatistas que se iniciavam com a Sexta Declaração, daí a expressão "aderentes da Sexta" utilizada pelo movimento para se referir aos aliados do zapatismo na sociedade civil (DIEZ, 2011). A economia política internacional é recorrente para a análise crítica do cenário mexicano, e por isso a noção ampla da resistência de forma transnacional e solidária.

Desde 2003 a autonomia já passava por um processo de "institucionalização" interna com o desenvolvimento das JBG e os Caracóis, que esteve relacionada também com a necessidade de melhor distribuição/ coordenação dos auxílios internacionais. Sobre isso, dizem:

(...) melhorou muito o apoio da sociedade civil nacional e internacional, porque antes cada um iam onde lhe dava na telha, e agora as Juntas de Bom Governo orientam em relação aonde é mais necessário. E, por isso mesmo, por toda parte, há mais companheiros e companheiras que estão aprendendo a relacionar-se com as pessoas de outras regiões do México e do mundo, estão aprendendo a respeitar e a exigir respeito, estão aprendendo que há muitos mundos e que todos têm o seu lugar, seu tempo, seu jeito, e temos que nos respeitar mutuamente entre todos (EZLN, 2017c).

Para reduzir a desigualdade entre as comunidades indígenas foi essencial conseguir a organização dos projetos externos que rece- 
biam, os quais eram muitas vezes direcionados para as regiões com maior proximidade em relação à sociedade civil. É interessante analisar como o modelo de solidariedade no caso zapatista se distingue da tradição "solidária" entre o Norte o Sul nas relações internacionais. Diferente da perspectiva muitas vezes de caridade envolvendo os auxílios provenientes do Norte aos países do Sul, a solidariedade zapatista se baseia na horizontalidade e no respeito mútuo entre os interlocutores (OLESEN, 2004b).

Além disso, não se trata aqui de uma solidariedade material para favorecer o desenvolvimento econômico local na perspectiva de administração dos problemas sociais, mas sim do entendimento entre os sujeitos sobre a origem do problema: o neoliberalismo/globalização (OLESEN, 2005). A atividade de estabelecer como e aonde seriam realizados os apoios na região zapatista, e não a apenas a aceitação do auxílio influenciou a própria maneira de organização das ONGs originadas no Sul Global, as quais muitas vezes eram subordinadas aos modelos e agendas das ONGs do Norte, que contavam como mais expertise e recursos (ANDREWS, 2010).

A representação da guerra mundial da Declaração da Realidade permaneceu no discurso zapatista:

Então os capitalistas globalizados se metem a todos os lados, ou seja, a
todos os países, para fazer seus negócios, ou seja, suas grandes explora-
ções (...). Por isso nós zapatistas dizemos que a globalização neoliberal é
uma guerra de conquista de todo o mundo, uma guerra mundial, uma
guerra que faz o capitalismo para dominar mundialmente. E então essa
conquista as vezes é com exércitos que invadem um país e a força o con-
quistam. Mas as vezes é com a economia, ou seja, que os grandes capi-
talistas metem seu dinheiro em outro país ou lhes emprestam dinheiro,
mas com a condição de que obedeça ao que eles dizem. E também se
metem com suas ideias, ou seja, com a cultura capitalista que é a cultura
do mercado, da ganância do mercado (EZLN, 2017c).

Como resultado da hegemonia nas relações internacionais, percebemos a menção ao uso do poder bélico e das instituições internacionais na manutenção dos interesses da classe dominante, os "capitalistas globalizados". A subordinação nas relações econômicas mundiais por meio da capacidade ordenadora de instituições como o Banco Mundial e o Fundo Monetário Internacional (FMI) é histórica no desenvolvimento do neoliberalismo no México, que acabou se tornando refém dos empréstimos monetários realizados para solucionar a crise da própria liberalização motivada e defendida por esses organismos.

Outro elemento importante mencionado aqui é a "cultura capitalista", isto é, a prática social voltada exclusivamente para o consumo e acumulação de riqueza, a civilização de mercado. Além da questão sobre a democracia, outros pontos podem ser elencados sobre como o zapatismo desafia a "cultura capitalista", por exemplo, a ecologia. A ideia de preservação do meio-ambiente na prática zapatista, isto é, a relação entre o sujeito e a terra, a natureza não como um objeto externo a ser dominado, mas sim como parte integrante do desenvolvimento social vai além do que o ambientalismo corporativo pode aceitar. É nesse sentido que os direitos indígenas ameaçam as ideias capitalistas, quando a reprodução do ciclo de acumulação é limitada pelo primeiro (HARVEY, 2016). 
10. 0 suposto caráter social do Programa Nacional de Solidariedade (PRONA-

SOL) se tratava de um transformismo baseado na cooptação das "decisões democráticas" e auxílios paliativos. Com o discurso de sociedade civil neoliberal, o controle do Estado sobre as organizações de administração pública se tornou ainda mais centralizado pela elite tecnocrata do PRI e reforçava as relações de poder dos caciques nas comunidades dos estados do sul, ao passo que o Estado alegava ampla participação popular nas decisões sociais

(CAULFIELD, 1998).

11. Companhia Nacional de Subsistências Populares (CONASUPO) era uma importante instituição para a manutenção do poder de compra

da classe trabalhadora nos produtos alimentícios agrícolas básicos e a renda do pequeno agricultor, por meio do controle dos preços, subsídios, redução de custos e monopólio da compra de safras internacionais. Com os privilégios e participação nas atividades econômicas a empresa teve seu papel reduzido drasticamente, de modo que em 1991 as atividades passaram a ser geridas pela Agência de Serviços para a Comercialização e Desenvolvimento dos Mercados Agropecuários (ASERCA). (YUNES-NAUDE, 2003)
Quando algumas perspectivas analisam a mobilização das forças transnacionais no caso zapatista é muito recorrente a defesa de que a identidade construída transcenderia as questões de classe no conceito de democracia radical defendida pelos rebeldes, e por isso seria pós-moderno (JEFFRIES, 2001). De fato, já relatado anteriormente, o discurso zapatista consegue se articular com as diversas formas de exploração e opressão da sociedade na globalização. Contudo, a capacidade de diálogo plural com outros sujeitos marginalizados não retira o caráter de classe no discurso zapatista, ainda que este não recorra ao termo "classe". Vejamos:

\footnotetext{
(...) no campo está acontecendo igual foi no "Porfirismo", nada mais que, em lugar de fazendeiros, agora são umas empresas estrangeiras as que tem o trabalhador da terra bem oprimidos. E onde antes havia crédito e preços de proteção, agora só há esmolas (...). Por sua vez o trabalhador da cidade, as fabricas fecham e ficam sem trabalho, ou se abrem as que se chamam maquiladoras, que são do estrangeiro e que pagam uma miséria por muitas horas de trabalho. (...) E o que está acontecendo é que o México está se convertendo, nada mais, onde se nasce em um momento, e outro momento se morre, os que trabalham para a riqueza dos estrangeiros principalmente dos estadunidenses ricos. (...) E também, disseram que vão privatizar, ou seja, vender aos estrangeiros, as empresas que tinham o Estado para apoiar o bem-estar do povo. (...) E, também, disseram que se tem que abrir as fronteiras para que entre todo o capital estrangeiro, que assim vão preocupar-se mais os empresários mexicanos e fazer melhor as coisas. Mas agora vemos que já nem tem empresas nacionais, tudo foi comido pelos estrangeiros. (EZLN, 2017c).
}

Apesar da permanência da representação da globalização enquanto uma guerra mundial do capital, tendo esse enquanto agente próprio, outros elementos ganham mais forças no discurso, como é o caso do "capital estrangeiro/estadunidense rico/empresário mexicano". A representação dos zapatistas sobre esses atores fornece traços sobre a agência na arquitetura nacional/internacional, o que nos leva a refletir sobre a imagem de uma CCT, e as relações sociais de produção decorrentes de sua liderança material e ideológica no histórico do (não-)desenvolvimento econômico do México. Percebemos no texto os efeitos (simbolizados principalmente pelo PRONASOL ${ }^{10}$ de Salinas de Gortari) que a revolução passiva promoveu nas bases do modo de produção, orquestrada pelo interesse da classe dirigente mexicana em se manter no poder em conjunto com o movimento das corporações transnacionais em busca do crescimento de suas taxas de lucro. Primeiro é mencionada a situação dos trabalhadores rurais/camponeses, contrapondo-se aos direitos trabalhistas e às iniciativas de inserção do pequeno agricultor na economia, os quais eram garantidos em outros momentos (vide CONASUPO ${ }^{11}$ ).

Em segundo temos a menção à condição dos trabalhadores urbanos. A superexploração da força de trabalho é representada pelo modo de produção das maquiladoras, que garantem o lucro por meio da exploração das condições de trabalho. Além disso, os zapatistas se demonstram conscientes em relação a informalidade crônica mexicana, bem como o domínio do capital estrangeiro sobre as formas de organização dos trabalhadores, e a crise de geração de empregos, elemento discursivo do Estado essencial para a operacionalização do ALCAN. Ao fim e ao cabo, tanto a classe dominante mexicana, quanto a estadunidense são interligadas pela "redução de barreiras" do mercado e consideradas responsáveis pelo descolamento da realidade social com a economia. 
Para Andrews (2010), a Sexta Declaração e a Outra Campanha motivaram atores da sociedade civil internacional organizada, que participam da rede de solidariedade, a se voltarem também para as dificuldades encontradas localmente, da onde essas organizações partem. Desde então, os zapatistas se esforçaram principalmente para a construção interna da autonomia e focaram a questão da solidariedade transnacional em relação às práticas locais que podem ser efetuadas, para além de Chiapas. Além disso, importantes debates e conferências sobre o papel da ciência e o auxílio material foram efetuados para a criação de um conhecimento que não seja instrumental. O projeto da Escuelita Zapatista realizado em 2013 e 2014 surge como método de entender a autonomia dos zapatistas por aqueles que buscam colocar em prática esse princípio no seu contexto social. Participantes de diversas nacionalidades participaram do cotidiano do "bom governo", o objetivo era aprender como se dá na realidade (benefícios e obstáculos) a construção da autonomia nos 3 níveis de governo: regional, municipal e comunal (GOMEZ, 2014). As famílias zapatistas receberam os participantes para uma experiência de vivência, nas qual aqueles que acompanham o zapatismo de longe puderam participar do mandar-obedecendo (CONCHA, 2013).

O movimento zapatista se encontra (re)rotacionando, visto que pela primeira vez desde 1994 será lançada a candidatura para a disputas presidenciais de uma mulher indígena independente escolhida democraticamente pelo EZLN e o Congresso Nacional Indígena (CNI), María de Jesús Patricio Martínez (chamada de Marichuy pelos apoiadores). E mais uma vez as organizações presentes na sociedade civil internacional que se solidarizam com a luta zapatista estão apoiando uma campanha política por democracia no México a partir da ação dos indígenas/camponeses rebeldes em aliança com outros setores populares mexicanos (NAVARRO, 2017).

O fato é que as condições de GBI e dificuldades materiais presenciadas nos territórios autônomos se demonstram persistentes devido principalmente ao desgaste em relação a manutenção da auto-organização política frente ao poder beligerante do Estado mexicano (PRI/PAN). Ainda que a transformação da sociedade se dê (também) no processo molecular de crítica sobre a dominação ideológica na sociedade civil, as instituições da sociedade política não podem ser negligenciadas nesse processo. Entretanto, tal candidatura não deve ser interpretada como uma corrida eleitoral tradicional pelo poder, e tampouco enquanto um "chiste". Os esforços para garantir a sua participação são reais ${ }^{12}$, porém transbordam as premissas de uma eleição comum, sendo a movimentação de forças contestatórias no cerne da política mexicana o principal objetivo (ZAGATO, 2017).

Zapatismo e o internacionalismo

A experiência zapatista, portanto, motiva-nos a pensar sobre a questão da construção de uma contra-hegemonia, a qual seja capaz de articular também a dimensão das forças sociais transnacionais, dentro da análise geopolítica gramsciana da realidade nacional e internacional. Duas questões nos parecem pertinentes nesse momento, (i) a territorialização da luta em si, isto é, contra quem e como se está lutando na globali-
12. Será necessário o recolhimento de 867.000 assinaturas entre no mínimo 17 estados do México até a data 12 de fevereiro de 2018 para oficializar a sua excepcional candidatura, o que requer um trabalho árduo de toda a militância zapatista (ZAGATO, 2017). 
zação, e (ii) a participação de atores da sociedade civil internacional como ONGs e ONGIs junto com os movimentos sociais.

Muitas narrativas levam em consideração a ampla gama de atores presentes na sociedade civil internacional como emancipatório per se "Sociedade Civil Global" (SCG) - e se assemelham ao discurso cosmopolita da CCT. Em relação ao cosmopolitismo encontramos na obra de Gramsci passagens que nos levam a repensar o caráter universalista defendido por esta perspectiva, como, por exemplo, na "questão da língua". $\mathrm{O}$ autor preocupado em como a formação intelectual da elite italiana influenciada pela Igreja Católica era mais associada aos interesses estrangeiros, do que à cultura popular discute a relevância da associação entre a linguagem e as massas na construção de uma imagem nacional-popular e da vontade coletiva, dificultando a própria formação do Estado-nação italiano (IVES \& SHORT, 2012).

Desse ponto de vista, a SCG seria um carro-chefe para a cristalização dos interesses da globalização por cima através da legitimidade de um ator "emancipatório" derivado da mesma "comunicação" entre os envolvidos. Entretanto, outro problema que deve ser evidenciado são as leituras que consideram também a arena de disputa da sociedade civil internacional de forma homogênea, porém enquanto um dispositivo de controle para os problemas sociais do neoliberalismo, e, portanto, de manutenção do status-quo (LIPSCHUTZ, 2005). Não só o zapatismo, mas outros movimentos sociais contrariam essa perspectiva e demonstram como a solidariedade transnacional pode ser transformadora e anticapitalista.

Quando pensamos a prática para transformar a realidade da globalização se torna difícil compreender como efetuá-la, uma vez que o arranjo da hegemonia nas instituições internacionais é bastante complexo para manifestações/ações concretas que tragam um resultado positivo de longo prazo. Tendo em mente essa problemática, Mcnally (2009) recorre ao internacionalismo de Gramsci para pensar como é possível construir um outro mundo, de fato. A tradição do internacionalismo comunista ficou muito marcada pela imposição soviética do que seria o modelo "oficial" a ser seguido como revolucionário para o recebimento de auxílios na condução dos conflitos domésticos (ANGELIS, 2000).

Contudo, a visão de Gramsci se distingue dessa interpretação:

Por certo, o desenvolvimento é no sentido do internacionalismo, mas o ponto de partida é "nacional", e é deste ponto de partida que se deve partir. Mas a perspectiva é internacional e não pode deixar de ser. É preciso, portanto, estudar exatamente a combinação de forças nacionais que a classe internacional deverá dirigir e desenvolver segundo a perspectiva e as diretrizes internacionais. A classe dirigente só será dirigente se interpretar exatamente esta combinação da qual ela própria é componente, e só como tal pode dar ao movimento uma determinada orientação, de acordo com determinadas perspectivas (GRAMSCI \& COUTINHO, 2011, pp. 265 - 266).

A noção do que é nacional para Gramsci não se trata apenas da visão unilateral de uma classe sobre a forma do Estado, mas atravessa debates pertinentes sobre a cultura popular e a participação democrática das massas - com o diálogo entre suas diversas opressões - na construção do nacional-popular. Portanto, o internacionalismo gramsciano se direciona para a solidariedade de classe junto com a compreensão dos distintos mo- 
vimentos originados a partir de características específicas dos respectivos Estados em que estão inseridos. Seria, então, a internacionalização do movimento revolucionário (MCNALLY, 2009).

Talvez o que mais prejudique a análise das forças sociais progressistas na dimensão transnacional seja justamente o deslocamento para a resistência do espaço de agência, como é o caso do altermundialismo (RAMOS, 2006). Mesmo que a resistência esteja conectada a um modelo político e econômico global, reproduz-se em um determinado território local/nacional (por isso os limites de se pensar a existência, de fato, da sociedade civil global, mais sim em atores nacionais/internacionais organizados transnacionalmente), sendo capaz de projetar/modificar a sua realidade local, na qual é possível consolidar um projeto nacional-popular (GRAMSCI, 2000; MORTON, 2007). Ao mesmo tempo, este projeto nacional-popular passa a demandar cada vez mais forças externas (solidariedade transnacional) para lidar com as forças sociais da revolução passiva, o que Gramsci se referia à internacionalização do movimento operário (MCNALLY, 2009). Os movimentos sociais de luta pela terra que surgem por todo o globo precisam se manter, por exemplo, com a máquina repressiva do Estado sob constante ameaça e criminalização (MORTON, 2007).

A partir do pensamento da internacionalização é possível um melhor entendimento quando analisamos as camadas de forças sociais presentes em Chiapas. O movimento zapatista em sua trajetória nunca se desvinculou da realidade chiapaneca e da nação mexicana. Ao contrário, é por meio da inserção do México nas relações internacionais que os zapatistas interpretam tão profundamente o que é a globalização. Essa interpretação estimulou o movimento a conciliar as forças sociais transnacionais com o caminho que o movimento decidiu construir (OLESEN, 2005).

A rede de solidariedade transnacional ocorre como um desdobramento da práxis zapatista, e se torna um elemento essencial para o desenvolvimento do movimento no seu estágio atual. E assim os zapatistas dizem:

Se você olha para um desses estudos feitos pelos governos, vai ver que as únicas comunidades indígenas que melhoraram suas condições de vida, ou seja, sua saúde, educação, alimentação, moradia, foram as que estão em território zapatista, que é como nós chamamos o lugar onde estão nossos povoados. E tudo isso tem sido possível pelo avanço dos povoados zapatistas e pelo apoio muito grande recebido de pessoas boas e nobres, que chamamos de "sociedades civis", e de suas organizações no mundo inteiro. (EZLN, 2017c).

Na manutenção de um processo revolucionário que altera as relações sociais da sociedade civil com o Estado mexicano, na economia política, que reside o principal fator emancipatório da rede transnacional de solidariedade zapatista. É assim que a globalização é paulatinamente superada. Isso não quer dizer que outros atores/movimentos não se beneficiem com a rede, até porque exclusividade não era o propósito dos zapatistas com o seu engajamento na criação de espaços de compartilhamento das resistências, mas sim que ela deixa de ser algo episódico para se concretizar no autogoverno rebelde.

Os princípios de horizontalidade e reciprocidade da prática discursiva zapatista em que se originou a rede de solidariedade influenciou bastante a forma que o altermundialismo tomou, o que é positivo, pois é no 
13. 0 termo é de extrema relevância para a esquerda, visto que nos ajuda a identificar como práticas possivelmente ameaçadoras são aderidas às políticas do status-quo e domesticadas, evitando a mobilização das massas (COX, 1983) entendimento mútuo das semelhanças e diferenças que é possível se pensar na construção do bom senso. Porém, como ressalta Fairclough (2010), o discurso hegemônico é colonizador, e para o seu ordenamento da prática social outros discursos são absorvidos na interdiscursividade. O que põe em debate a presença do transformismo ${ }^{13}$ na resistência mundial.

Stephen Gill (1995b) quando caracteriza o panoptismo para a liberalização global do sistema financeiro internacional menciona a vigilância praticada pelos Estados e agências internacionais por meio da tecnologia, principalmente no sistema de créditos bancários. Ele também aborda a tecnologia para se referir às atividades dos ativistas contra a globalização de cima, caracterizando-as como uma vigilância democrática interconectada globalmente. As bases do modo de produção capitalista flexível também fornecem meios para a contestação dos abusos do poder hegemônico por movimentos sociais, ativistas, ONGs e organizações de investigação independentes. Bieler e Morton (2006) analisam que o modo de produção capitalista sempre foi em sua essência global, o que muda no nosso momento histórico de globalização é a forma que esse assume. Com a transnacionalização da economia mundial, as classes trabalhadoras buscam forças no cenário internacional para auxiliá-las na condução de suas respectivas agendas de luta no contexto em que estão inseridas.

Nesse sentido, as organizações presentes na sociedade civil internacional (ONGs, ONGIs, por exemplo) participam da luta de classes justamente devido à sua ação frente a esses movimentos, isto é, favorecendo-os ou dificultando o avanço de suas pautas direta ou indiretamente. Portanto, ainda que os atores não sejam declaradamente favoráveis aos interesses de uma determinada classe, o seu envolvimento deve ser compreendido a partir da luta de classes (BIELER \& MORTON, 2006).

Ao mesmo tempo que existem ONGs na resistência ao lado dos movimentos sociais, outras aproveitam o espaço de abertura do diálogo e construção para reproduzir os interesses hegemônicos. Isso se torna mais evidente no caso do Fórum Social Mundial (FSM), no qual a participação dos movimentos sociais tem sido subordinada à agenda tecnicista de muitas ONGs que ocupam o centro da coordenação do fórum por meio do discurso de "melhor desempenho" e "eficiência" do design das ONGs (ARIAS, 2015). Praticamente uma concepção neoliberal do que seria a sociedade civil, ou melhor, o terceiro setor.

Considerações finais

Acreditamos que a construção da história acontece não apenas pelos movimentos das elites, mas também pelos movimentos populares, e vivenciamos um importante estágio de autocrítica e fortalecimento das forças sociais de esquerda. Se almejamos uma solidariedade transnacional capaz de resistir/transformar o status-quo globalizante, devemos nos atentar para os riscos de transformismo e analisar quais são aqueles que estão nos acompanhando nessa "guerra mundial", além de ter em mente como materializar diretamente nossas demandas contra o neoliberalismo disciplinar, dentro das especificidades de cada Estado componente do sistema interestatal moderno, sem excluir a dimensão transnacional no decorrer da guerra de posição. 
Os esforços do zapatismo em construir um outro mundo são repletos de dilemas, desafios e controvérsias. Mas também são preenchidos por conquistas, avanços e esperança. Uma de suas contribuições foi a demonstração de que é possível alterar a posição de subalternidade, em um momento que a ideia hegemônica de liberdade e democracia significa a exclusão da dignidade. Mas isso não é possível sozinhos, a solidariedade construída historicamente também desempenha o seu papel, a qual os zapatistas humildemente reconhecem.

Referências

ALVES, Ana Rodrigues Cavalcanti. O conceito de hegemonia: de Gramsci a Laclau e Mouffe. Lua Nova, São Paulo, v. 80, n. 71-96, p. 71, 2010.

ANDREWS, Abigail. How activists "take zapatismo home": South-to-north dynamics in transnational social movements. Latin American Perspectives, Vol 38, Issue 1, p. 138-152, 2010.

ANGELIS, Massimo De. Globalization, new internationalism and the Zapatistas. Capital \& Class, v. 24, n. 1, p. 9-35, 2000.

ARIAS, Santiane. O Altermundialismo no campo das lutas contra-hegemônicas: a tensão em torno do projeto político social. Temáticas, n. 45/46, 2016.

BIELER, Andreas; MORTON, Adam. Class Formation, Resistance and the Transnational. In: BIELER, Andreas; BONEFELD, Werner; BURNHAM, Peter; MORTON, Adam (orgs). Global Restructuring, State, Capital and Labour. Palgrave Macmillan UK. p. 196-206. 2006.

BIELER, Andreas; MORTON, Adam. The deficits of discourse in IPE: Turning base metal into gold?. International Studies Quarterly, v. 52, n. 1, p. 103-128, 2008.

BRANCALEONE, Cássio. Teoria Social, Democracia e Autonomia: Uma interpretação da experiência de autogoverno zapatista. 1 ed. Rio de Janeiro: Beco do Azougue, 2015.

CARROLL, William K.; SAPINSKI, Jean Philippe. The global corporate elite and the transnational policy-planning network, 1996-2006: A structural analysis. international Sociology, v. 25, n. 4 , p. 501-538, 2010.

CAULFIELD, Norman. Mexican workers and the state: From the Porfiriato to NAFTA. Texas Christian University Press, 1998.

CECEÑA, Ana Esther. Por la humanidad y contra el neoliberalismo. Líneas centrales del discurso zapatista. Observatorio Social de América Latina, v. 3, p. 25-30, 2001.

CONCHA, Miguel. La Escuelita zapatista. La Jornada. Mexico. 2013.

GRAMSCI, Atonio; COUTINHO, Carlos Nelson. O leitor de Gramsci: escritos escolhidos 19161935. Rio de Janeiro: Civilização Brasileira, 2011.

COX, Robert W. Gramsci, hegemony and international relations: an essay in method. Cambridge Studies in International Relations, v. 26. 1983.

COX, Robert W. Production, power, and world order: Social forces in the making of history. Columbia University Press, 1987.

COX, Robert W. Social forces, states and world orders: beyond international relations theory. Millennium, v. 10, n. 2, p. 126-155, 1981.

DIEZ, Juan. El zapatismo es un verbo que se escribe en gerundio. Las rearticulaciones e interacciones al interior del movimiento zapatista. A Contracorriente (Raleigh: NCSU), v. 8, n. 2, 2011.

DELLACIOPPA, K; WEBER, Clare. Cultural Politics and Resistance in the 21st Century: Community-based Social Movements and Global Change in the Americas. Springer, 2012.

EZLN. Primera Declaración de La Realidad. Contra el neoliberalismo y por la humanidad. Disponível em: < http://enlacezapatista.ezln.org.mx/1996/01/01/primera-declaracion-de-la-realidad-contra-el-neoliberalismo-y-por-la-humanidad/>. Acesso em: 12 de fevereiro de 2017a.

EZLN. Segunda Declaración de La Realidad por la Humanidad y contra el Neoliberalismo. Disponível em: <http://enlacezapatista.ezln.org.mx/1996/08/03/segunda-declaracion-de-la-realidad-por-la-humanidad-y-contra-el-neoliberalismo/>. Acesso em: 12 de fevereiro de 2017b. 
EZLN. Sexta Declaración de la Selva Lacandona. Disponível em: < http://enlacezapatista. ezln.org.mx/sdsl-es/>. Acesso em: 19 de fevereiro de 2017c.

FAIRCLOUGH, Norman. Critical discourse analysis: The critical study of language. Routledge, 2010.

GILL, Stephen. Globalisation, market civilisation, and disciplinary neoliberalism. Millennium-Journal of International Studies, v. 24, n. 3, p. 399-423, 1995a.

GILL, Stephen. Power and Resistance in the New World Order: Fully Revised and Updated. Palgrave Macmillan, 2008.

GILL, Stephen. The global panopticon? The neoliberal state, economic life, and democratic surveillance. Alternatives, v. 20, n. 1, p. 1-49, 1995b.

GÓMEZ, Magdalena. La escuelita y el poder civil zapatista. La Jornada. Mexico. 2014.

GRAMSCI, Antonio; COUTINHO, Carlos Nelson. Cadernos do cárcere. Rio de Janeiro: Civilização Brasileira, 2000.

HARVEY, Neil. Practicing autonomy: Zapatismo and decolonial liberation. Latin American and Caribbean Ethnic Studies, v. 11, n. 1, p. 1-24, 2016.

HILSENBECK, Alexander. Zapatismo: Entre a guerra de palavras e a guerra pela palavra. Disponível em: <http://passapalavra.info/2009/04/2677>. Acesso em: 12 set. 2016

IVES, Peter. Language and hegemony in Gramsci. London: Pluto Press, 2004.

IVES, Peter; SHORT, Nicola. On Gramsci and the international: a textual analysis. Review of International Studies, v. 39, n. 03, p. 621-642, 2013.

JEFFRIES, Fiona. Zapatismo and the intergalactic age. Globalization and Postmodern Politics: From Zapatistas to High-Tech Robber Barons, p. 129-144, 2001.

KHASNABISH, Alex. Zapatistas: Rebellion from the Grassroots to the Global. Zed Books Ltd. London. 2013.

LIPSCHUTZ, Ronnie. Global civil society and global governmentality: or, the search for politics and the state amidst the capillaries of social power. Power in global governance, p. 229$248,2005$.

MCNALLY, Mark. Gramsci’s internationalism, the national-popular and the Alternative Globalisation Movement. In: MCNALLY, Mark; SCHWARZMANTEL, John (Ed.). Gramsci and global politics: Hegemony and resistance. Nova York: Routledge, 2009.

MORTON, Adam. Revolution and State in Modern Mexico: The Political Economy of Uneven Development. Rowman \& Littlefield, 2013.

MORTON, Adam. Unravelling Gramsci: hegemony and passive revolution in the global political economy. Pluto Pr, 2007.

NAVARRO, Luis Hernández. Marichuy, una campaña muy otra. Disponível em: <http:// www.jornada.unam.mx/2017/10/17/opinion/021a2pol> Acessado em 07 de novembro de 2017.

NILSEN, Alf. 'The authors and the actors of their own drama': Towards a Marxist theory of social movements. Capital \& Class, v. 33, n. 3, p. 109-139, 2009.

OLESEN, Thomas. Globalising the Zapatistas: from Third World solidarity to global solidarity?. Third World Quarterly, v. 25, n. 1, p. 255-267, 2004b.

OLESEN, Thomas. Mixing Scales: Neoliberalism And The Transnational Zapatista Solidarity Newtwork. Humboldt Journal of Social Relations, v. 29, n. 1, p. 84-126, 2005.

OLESEN, Thomas. The transnational Zapatista solidarity network: an infrastructure analysis. Global Networks, v. 4, n. 1, p. 89-107, 2004a.

OUVIÑA, Hernán. La Política Prefigurativa de los Movimientos Populares en América Latina. Hacia una nueva matriz de intelección para las ciencias sociales. Acta Sociológica, v. 62, p. 77-104, 2013.

RAMOS, Leonardo César Souza. Civil society in an age of globalization: a neo-Gramscian perspective. Journal of Civil Society, v. 2, n. 2, p. 143-163, 2006.

ROBINSON, William I. Beyond the Theory of Imperialism: Global Capitalism and the Transnational State. Societies Without Borders, v. 2, n. 1, p. 5-26, 2007.

ROBINSON, William. Gramsci and Globalisation: From Nation-State to Transnational Hegemony. Critical Review Of International Social And Political Philosophy, v. 8, n. 4, p. 559-574, 2005. 
ROBINSON, William. Latin America and global capitalism: A critical globalization perspective. JHU Press, 2008.

ROVIRA, Guiomar. El zapatismo y la red transnacional. Razón y palabra, v. 47, 2005.

SANBONMATSU, John. The postmodern prince: Critical theory, left strategy, and the making of a new political subject. NYU Press, 2004.

SKLAIR, Leslie. The transnational capitalist class and global politics: deconstructing the corporate-state connection. International political science review, v. 23, n. 2, p. 159-174, 2002.

VAN DER PIJL, Kes. Transnational clas formation and state form. In: GILL, Stephen; MITTELMAN, James. Innovation and transformation in international studies. Cambridge University Press, 1997.

VÁZQUEZ-CASTILLO, Maria Teresa. Land Privatization in Mexico: Urbanization, Formation of Regions and Globalization in Ejidos. Routledge, 2004.

YUNEZ-NAUDE, Antonio. The dismantling of CONASUPO, a Mexican state trader in agriculture. The World Economy, v. 26, n. 1, p. 97-122, 2003.

ZAGATO, Alessandro. The popular movement and the electoral strategy. An indigenous candidate for Mexico. Disponível em: < https://libcom.org/news/popular-movement-electoral-strategy-indigenous-candidate-mexico-28092017 / > Acessado em: 07 de novembro de 2017. 